\title{
A narrative review of the current landscape and future perspectives of HER2-targeting antibody drug conjugates for advanced breast cancer
}

\author{
Hu Li, Hongfeng Li \\ Shanghai Miracogen, Shanghai, China \\ Contributions: (I) Conception and design: Hu Li; (II) Administrative support: Hu Li; (III) Provision of study materials or patients: Both authors; \\ (IV) Collection and assembly of data: Both authors; (V) Data analysis and interpretation: Hu Li; (VI) Manuscript writing: Both authors; (VII) Final \\ approval of manuscript: Both authors. \\ Correspondence to: Hu Li. Shanghai Miracogen, Suite 4E, Bldg. 3, No. 1238 Zhangiiang Road, Pudong District, Shanghai 201203, China. \\ Email: li_hu@miracogen.com.cn.
}

Objective: To (I) provide an update of approved antibody drug conjugates (ADCs) and those registered with NMPA, (II) give an overview of HER2-targeting ADCs as a mono- or combination therapy in clinical development for breast cancer and the molecular mechanism of payloads of these molecules, (III) describe the pharmacokinetic profiles of ADCs using mostly exploited vcMMAE platform as an example, (IV) discuss future development strategies for ADC therapeutics in addressing substantially unmet medical needs, such as brain metastasis (BM) and drug resistance in patients with HER2-expressing advanced breast cancer.

Background: As the most common type of cancer in women, breast cancer remains a significant challenge for drug discovery and development due to its heterogenous nature and complex molecular subtypes and pathologies. The advent of tyrosine kinase inhibitors (TKIs) and targeted therapies has significantly improved overall survival (OS) for breast cancer patients with early diagnosis, however, those who have experienced metastasis are still facing limited treatment options. ADCs are an emerging class of drugs used in targeted therapies for hematologic malignancies and solid tumors, known for their highly selective binding moiety of monoclonal antibody (mAb) to differentially expressed tumor antigens and highly cytotoxic warheads with defined mechanisms of action. Eleven ADCs have been approved by the FDA, three of which are for breast cancer indication namely HER2-targeting Kadcyla ${ }^{\circledR}$ and ENHERTU ${ }^{\circledR}$, and TROP2-targeting Trodelvy $^{\circledR}$, highlighting the clinical potential of this therapeutic modality for breast cancer treatment.

Methods: We searched relevant studies published in English in the PubMed, Informa PharmaProjects, ClinicalTrials.gov, FDA and EPO databases, google.com, and in Chinese in NMPA website up to Aug 9, 2021, using search strategies with search terms "HER2 ADC", "breast cancer", "antibody drug conjugate" (ADC), "PK/PD”, "linker", "payload”, “drug resistance”, and/or "brain metastasis".

Conclusions: In this review, we provide an update of HER2-targeting ADCs for breast cancer treatment, the types of payload used in these molecules, and the structures and mechanism of action of these payloads. We describe PK profile using vcMMAE platform and discuss future development strategies in addressing unmet medical needs such as CNS metastasis, HER2-low expression, and acquired drug resistance.

Keywords: Antibody drug conjugate (ADC); HER2; breast cancer; payload; brain metastasis (BM); drug resistance

Received: 13 August 2021; Accepted: 30 September 2021; Published: 31 October 2021.

doi: $10.21037 /$ tbcr-21-22

View this article at: https://dx.doi.org/10.21037/tbcr-21-22 


\section{Introduction}

Armed with both an antibody moiety that specifically recognizes tumor surface antigens and a potent cytotoxic warhead (payload) via a chemical linker of choice, antibody drug conjugates (ADCs) have been clinically proven as an important modality in treating patients with hematological malignancies and solid tumors (1). ADCs are comprised of three key components: the antibody, linker, and payload (see Figure 1). The primary function of the antibody component is to specifically target surface antigens of tumor cells, which are typically overexpressed compared to normal cells. This binding moiety can be in various forms, including monoclonal antibody (IgG), antibody fragment such as Fab, single-chain fragment variable ( $\mathrm{scFv}$ ), bispecific antibody (recognizing two different antigens on the same cell), biparatopic antibody (recognizing different epitopes on the same antigen), nanobody, etc. The function of the linker is to connect the payload to the antibody and control release of the payload, which is typically categorized as cleavable or non-cleavable. For cleavable linkers, low $\mathrm{pH}$, lysosomal enzymes, or reducing conditions could trigger cleavage depending on the nature of the linker chemistry, thus allowing the payload to escape the endosome or lysosome compartments to carry out cell killing duties. For noncleavable linkers, the antibody moiety has to be completely degraded in the lysosome compartment to enable the payload in its active form to release.

For most ADCs, whether approved or still in clinical trials, conjugation methods commonly include surface lysine residues or free-thiol groups of reduced cysteine from the interchain disulfides naturally occurring in the targeting antibody via maleimide or succinimide ester (2). In recent years, site-specific conjugation technologies or platforms have gained popularity. Examples of site-specific conjugation technologies include: (I) substituting certain amino acid residues with cysteines, non-natural amino acids or selenocysteine, or (II) modifying the sugars in the Fc fragment of the targeting antibody $(3,4)$. ADCs constructed by site-specific conjugation usually generate a more homogeneous drug to antibody ratio (DAR) species. Some have also been reported to demonstrate improved plasma stability among other features (4).

The function of the third component, payload, is to kill tumor cells. Since only a small percentage of ADCs administrated during treatment (e.g., $<1 \%$ ) are actually able to reach their targeted tumor tissues (5-7), the payload must possess highly potent cell killing capabilities (cytotoxicity) to successfully perform their intended function. Typically, this cytotoxicity is two to three orders of magnitude more potent than chemotherapy drugs (3). Cytotoxic compounds that meet the above criteria for being used as payloads in ADCs could hardly be directly administrated to patients due to intolerable systemic toxicities. The $\mathrm{IC}_{50}$ values of these compounds are typically between $10^{-6}-10^{-12} \mathrm{M}$ (Figure 2). In addition, the payload should not elicit immunogenicity, and its mechanism of action (MOA) should be well characterized. Based on MOA, compounds that are being evaluated as payloads in ADCs, both approved and in clinical trials, can be grouped into several classes (Table 1) $(8,9)$.

\section{Tubulin-binding class}

Representative agents in this class include maytansinoid, auristatin, tubulysin, hemiasterlin, cryptophycin, cemadotin, KSP (Kinesin spindle protein) inhibitor, among others. Most of them bind to the vinca site of $\beta$-microtubule and inhibit the polymerization of microtubule proteins. KSP inhibitors can block the separation of centrosomes in mitosis.

\section{DNA-damaging class}

Agents in this class can be further characterized as DNA intercalators, DNA double-strand breakers and DNA alkylators. DNA intercalators include topoisomerase inhibitors and they could cease the transcription and replication of DNA. Compounds of DNA double-strand breakers could induce cell death through cleaving DNA double chains at specific sites, and the enediyne moiety in the compound is critical for the chemical reaction to occur. DNA alkylators include Pyrrolo[2,1-c] [1,4] benzodiazepines (PBDs) and duocarmycins, which bind to DNA minor grooves and alkylate the guanine residues or adenine residues. ADCs with these payloads could potentially overcome multiple drug resistance (MDR) resulted from P-glycoprotein 1 (pgp-1) upregulation.

\section{Bcl- $x_{L}$ inbibitors class}

Bcl- $\mathrm{x}_{\mathrm{L}}$ proteins belong to the anti-apoptotic $\mathrm{Bcl}-2$ family and block the activity of pro-apoptotic $\mathrm{BH} 3$-domain proteins upon binding. The $\mathrm{Bcl}-\mathrm{x}_{\mathrm{L}}$ inhibitors could prevent this process from occurring. 


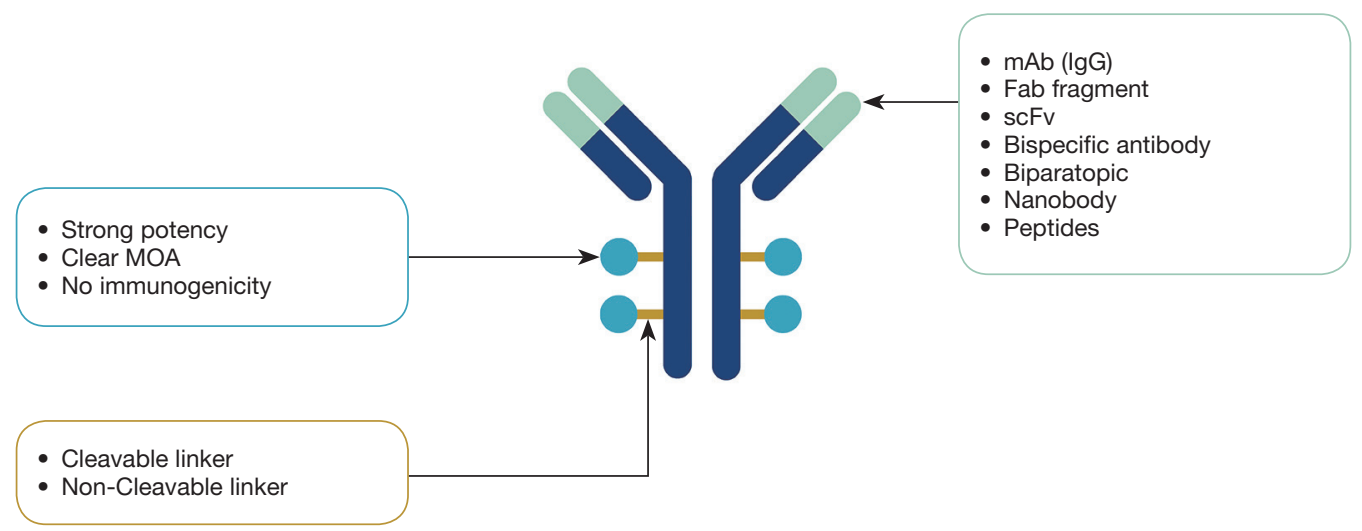

Figure 1 Components of an ADC. A typical ADC is composed of an antibody conjugated to a cytotoxic payload via a protease cleavable or non-cleavable linker. ADC, antibody drug conjugate.

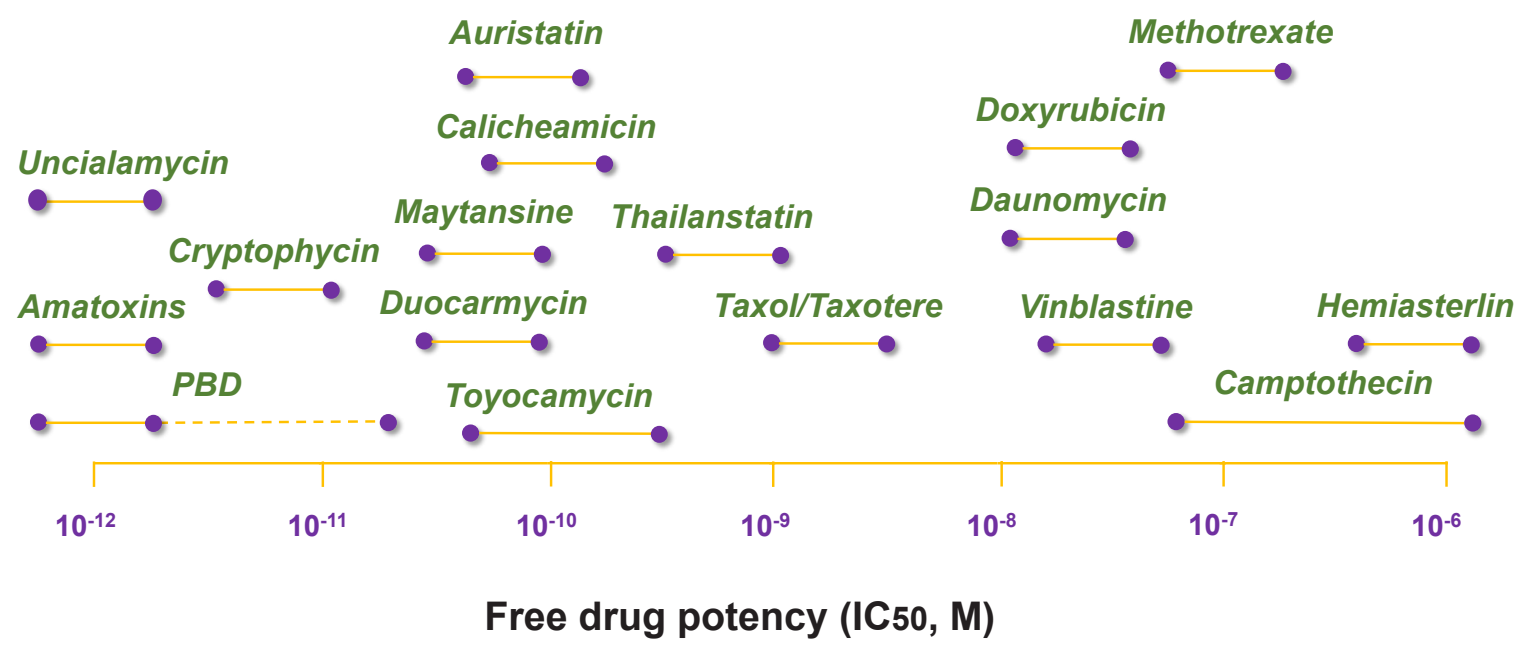

Figure 2 Potency spectrum of ADC payload classes. ADC, antibody drug conjugate.

\section{Spliceosome inhibitors class}

Many natural products belong to this class and they possess the high potency needed as the payload of ADC and could interfere the process of DNA translation through inhibiting RNA splicing and eventually cause tumor cell death.

\section{RNA polymerase inbibitors class}

$\alpha$-amanitin is one example of this compound class and functions to block the transcription process and subsequently induce cell apoptosis.

As of now, many compounds with the above MOA have been or are being evaluated as ADC payloads in the discovery and clinical stages and some of which have been tested in HER2-targeting ADCs for breast cancer, which will be discussed in a later section.

\section{Approved ADCs and those registered with NMPA}

Ever since the "Magic Bullet" concept was coined more than a century ago by German physician scientist and Nobel Laureate Paul Ehrlich (3), 11 ADCs have been approved by the FDA and, impressively, 7 out of which have been approved since 2019 alone (see Table 2). One novel ADC has obtained conditional approval from NMPA, but not the FDA, namely disitamab vedotin (RC-48) from RemeGen Biosciences, which is used to treat advanced gastric and gastro-esophageal junction (GEJ) cancer. In addition to these approved products, there are $90 \mathrm{ADCs}$ in clinical stage 
Table 1 Class of selected payloads used in ADCs by MOA

\begin{tabular}{|c|c|c|}
\hline MOA & Agents & Payload tested in ADCs \\
\hline \multirow{5}{*}{ Tubulin-binding class } & Auristatin & MMAD, MMAE, MMAF, etc. \\
\hline & Tubulysin & Tubulysin B, Tubulysin E \\
\hline & Hemiasterlin & HTI-286 \\
\hline & Cemadotin & $\mathrm{CemCH} 2-\mathrm{SH}$ \\
\hline & KSP inhibitor & Ispinesib, SB743921 \\
\hline \multicolumn{3}{|l|}{ DNA-damaging class } \\
\hline DNA intercalator & Camptothecin (Topo I inhibitor) & SN-38, DXd \\
\hline DNA double-strand breaker & Uncialamycin & NM \\
\hline \multirow[t]{2}{*}{ DNA alkylator } & Benzodiazepine dimer & PBD \\
\hline & Duocarmycin & Duocarmycin SA, Duocarmycin TM \\
\hline Bcl-xL inhibitor & NC & NM \\
\hline Spliceosome inhibitor & Thailanstatin & Thailanstatin A \\
\hline RNA polymerase Inhibitor & Amanitin & $\alpha$-Amanitin \\
\hline NKA inhibitor & Cardiac glycoside & NM \\
\hline $\begin{array}{l}\text { NAMPT-inhibitor (NAMPT: nicotinamide } \\
\text { phosphoribosyltransferase) }\end{array}$ & NC & $\begin{array}{l}\mathrm{N} \text {-(2-Fluoro-4-((1S,2S)-2-(pyridin-3-yl) } \\
\text { cyclopropanecarboxamido) benzyl)-4- } \\
\text { (piperazin-1- yl) benzamide }\end{array}$ \\
\hline
\end{tabular}

NC: only chemical structure could be found in literatures, but the categories of them haven't been reported. NM: only chemical structure could be found in literatures, but the names of them haven't been reported. ADC, antibody drug conjugate; MOA, mechanism of action.

and $190 \mathrm{ADCs}$ in preclinical development (10). As shown in Figure $3 A$, the number of ADCs registered with NMPA has increased significantly since 2016, and more ADCs from Chinese companies were registered with NMPA than foreign companies ever since. In addition to this increase, the diversity of targets is also evident in recent years. However, HER2 is still the most pursued target as 21 out of 55 registered ADCs are HER2-targeting ADCs, followed by five Trop2-targeting ADCs and four anti-Claudin 18.2 ADCs (Figure 3B).

\section{Mechanism of action and PK profiles of ADC}

The primary mechanism of action of ADCs is illustrated in Figure 4. First, the targeting moiety of the molecule (e.g., the antibody) binds to tumor cell surface antigens. The formed
ADC-antigen complex is then internalized via receptormediated endocytosis. Then, the complex is transported to lysosomes via intracellular trafficking pathways and subjected to proteolytic cleavage. Finally, the cytotoxic payload is released, which enters into the cell cytosol and induces cell death. Depending on the chemical properties of the cytotoxic payload and/or the design of the drug linker, the released active form of the payload can be either cell permeable or non-cell permeable. For the former, it possesses "bystander effect", i.e., ADCs with such payload can demonstrate cell killing capability for adjacent non-targeted cells in the tumor, examples of ADCs include Adcetris ${ }^{\circledR}$ and Enhertu ${ }^{\circledR}$. For the latter, it does not have "bystander effect", such ADC examples include Kadcyla ${ }^{\mathrm{TM}}$ and Blenrep ${ }^{\circledR}$.

Due to the complexity of the ADC molecule, the evaluation of its pharmacokinetics (PK) and 


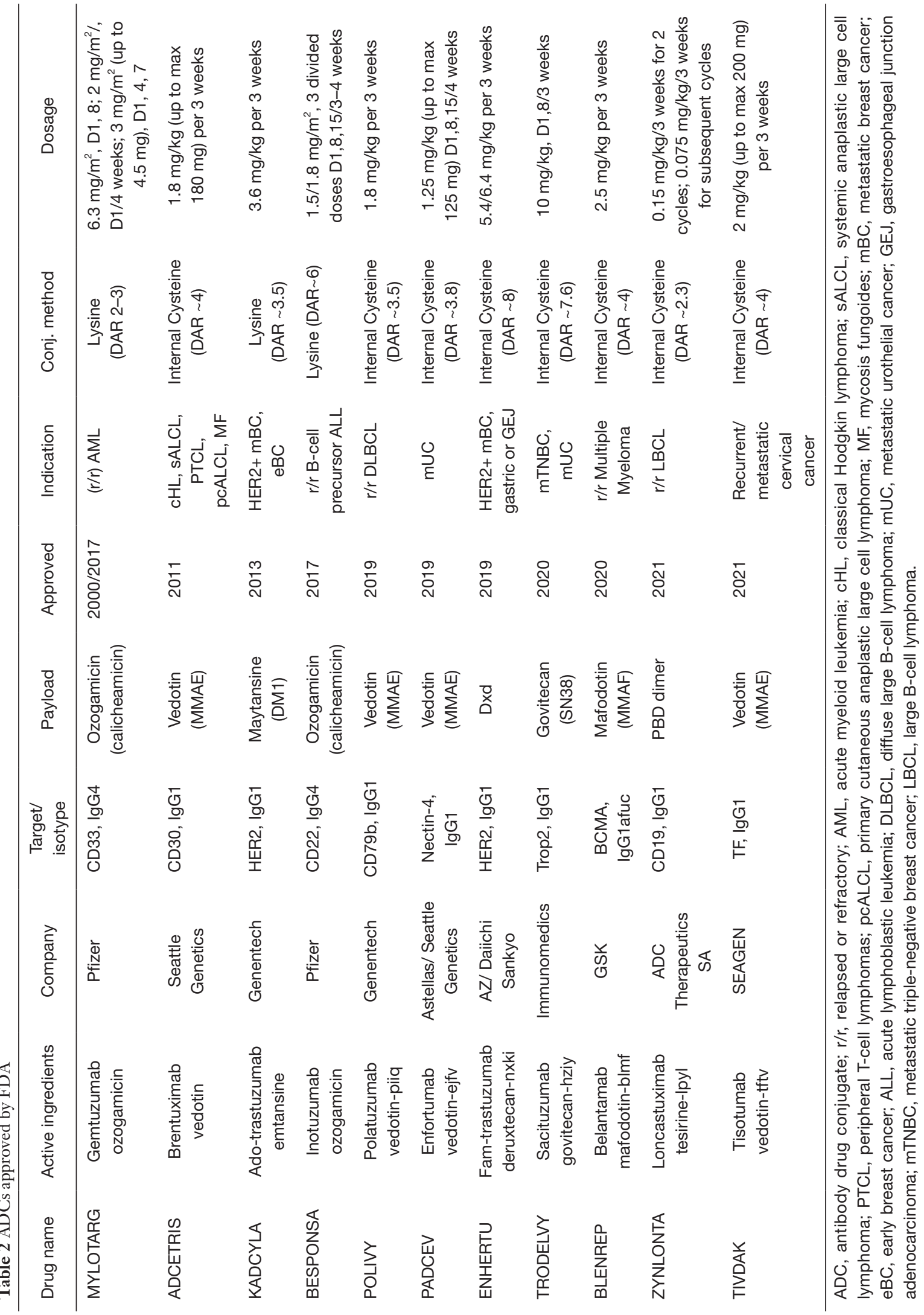




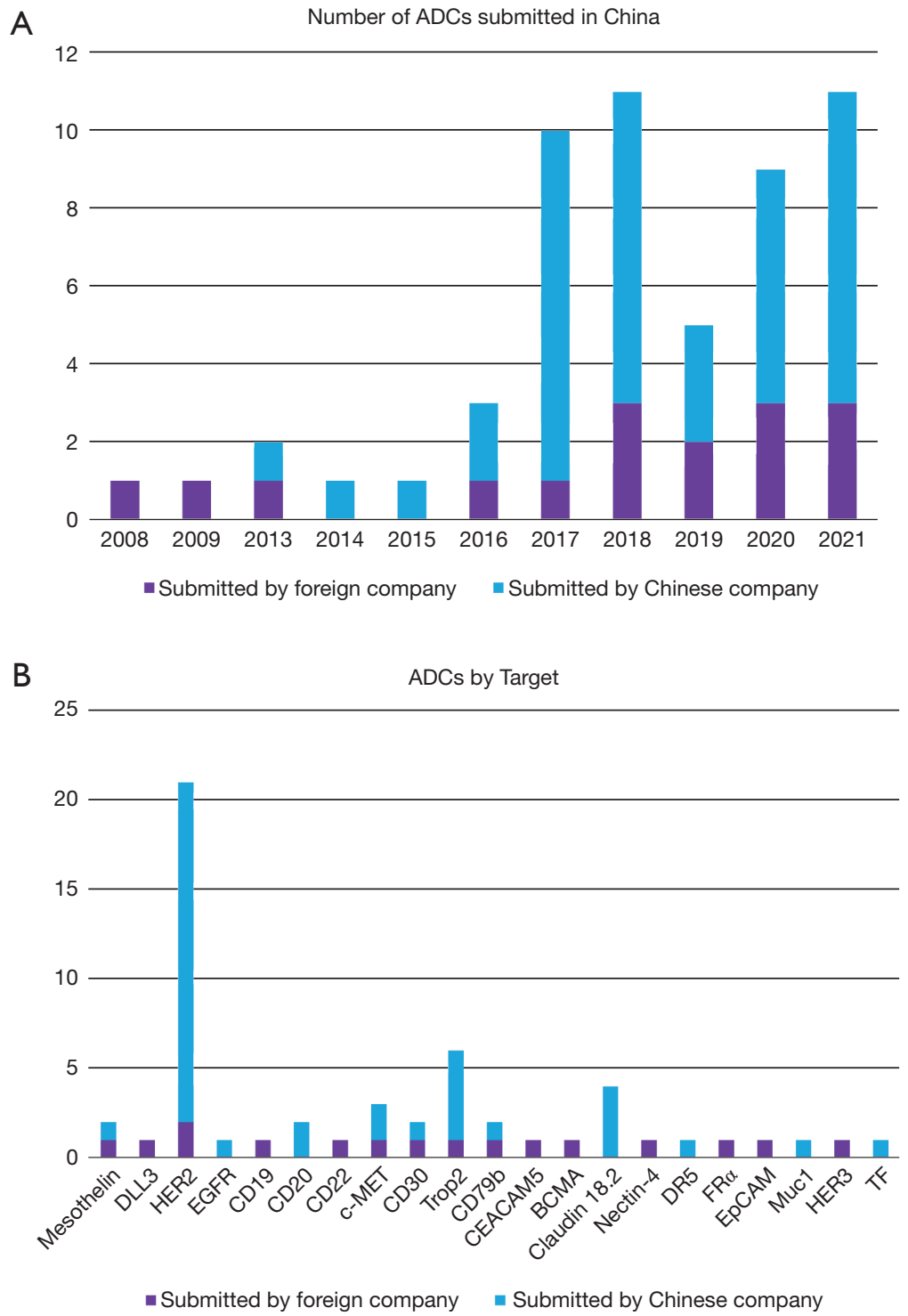

Figure 3 ADCs registered with NMPA. (A) Number of ADCs submitted in China from 2008 to 2021; (B) ADCs submitted by target from 2008 to 2021. Purple bar represents number of ADCs submitted by foreign company while blue bar represents number of ADCs submitted by Chinese company. Data cutoff is July 28, 2021. ADC, antibody drug conjugate; NMPA, National Medical Products Administration.

pharmacodynamics (PD) is also complicated. Once ADCs are administrated in vivo, three analytes in serum or plasma should be measured (11). These analytes are typically represented by the conjugated antibody (ADC), the total antibody (TAb) and the unconjugated payload, which is illustrated in Figure $5 \mathrm{~A}$. Conjugated antibody (ADC) species can be a mixture of ADCs with a different DAR value (DAR $>1)$, as is often the case with conventional conjugation methods, while total antibody $(\mathrm{TAb})$ includes the conjugated antibody and the naked antibody (unconjugated antibody). A typical PK profile of these three analytes of ADCs is illustrated in Figure 5B. If an $\mathrm{ADC}$ is stable after being administrated in vivo, the ADC concentration-time (CT) curve would closely follow that of the TAb as an insignificant amount of payload is released from the ADC during circulation. In this case, the PK behavior of the ADC is similar to that of the mAb (12), featured by a short Tmax (i.e., Cmax is typically observed right after intravenous infusion) and drug concentration declines multiexponentially over time. However, clearance 


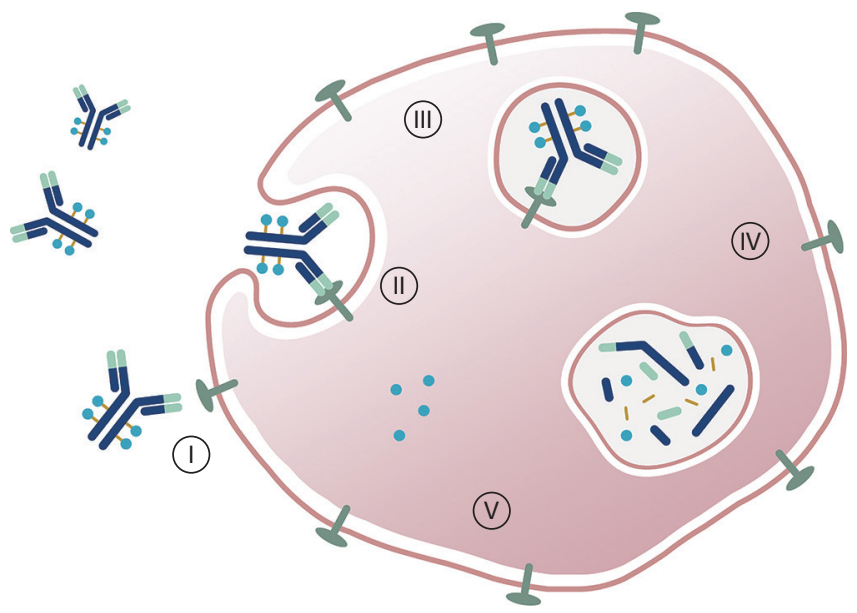

Figure 4 Mechanism of action of ADC. (I) Binding of ADC to cell surface antigen; (II) receptor mediated internalization of ADC-antigen complex; (III) complex is trafficked to the endosome; (IV) complex is transported to the lysosome; (V) payload released to cytosol. ADC, antibody drug conjugate.

of the ADC is usually faster than the TAb. In contrast, the unconjugated payload's PK behavior is confounded by formation-rated limited kinetics. Because drug release from the ADC partially determines its half-life $(13,14)$, its concentration-time (C-T) curve typically demonstrates a slow release. This is symbolized by a lagged Tmax and dramatically reduced Cmax compared to those of a free payload administrated with similar molarity (i.e., Cmax is often 2 to 3 orders of magnitude lower). This phenomenon is illustrated in Figure 5C.

In this review, we will provide the current landscape of HER2-targeting ADCs with emphases on payload types, structures and mechanism of actions of these payloads as well as the $\mathrm{PK}$ profile of the mostly exploited vcMMAE ADC. We will discuss strategies in addressing unmet medical needs for HER2-expressing breast cancer. We present the following article in accordance with the Narrative Review reporting checklist (available at https:// dx.doi.org/10.21037/tbcr-21-22).

\section{Methods}

We searched relevant studies published up to Aug 9, 2021 in English in the PubMed, Informa PharmaProjects, ClinicalTrials.gov, FDA and EPO databases, google.com, and in Chinese in NMPA website, using search terms such as "HER2 ADC", "breast cancer”, "ADC", "PK/PD”, "linker", "payload”, “drug resistance", and/or "brain metastasis".

\section{HER2 and breast cancer}

ERBB2 is a proto-oncogene of multiple cancers, including breast and gastric cancers, characterized by HER2 protein overexpression or ERBB2 gene amplification (15). HER2 overexpression accounts for approximately $20 \%$ of all forms of breast cancer $(16,17)$ and is closely related to increased malignancy and poor prognosis (18).

HER2 targeted therapeutics, such as monoclonal antibodies (e.g., trastuzumab and pertuzumab), and tyrosine kinase inhibitors (TKIs) (e.g., lapatinib), have shown significant clinical benefits for patients with early-stage and metastatic HER2-positive breast cancers. However, a large proportion of patients with HER2-positive breast cancer have shown de novo or acquired resistance to trastuzumab $(19,20)$.

\section{Approved HER2-targeting ADCs for breast cancer}

\section{T-DM1}

Ado-trastuzumab emtansine (T-DM1, Kadcyla ${ }^{\circledR}$ ), an ADC that links trastuzumab (humanized IgG1) through a nonreducible thioether linker SMCC [N-succinimidyl-4(N-maleimidomethyl) cyclohexane-1-carboxylate] to the small molecule toxin DM1 (maytansine) with a DAR of 3.5, has been approved for the treatment of patients with HER2-positive metastatic breast cancer (MBC) previously treated with trastuzumab and taxane $(21,22)$. However, 
A

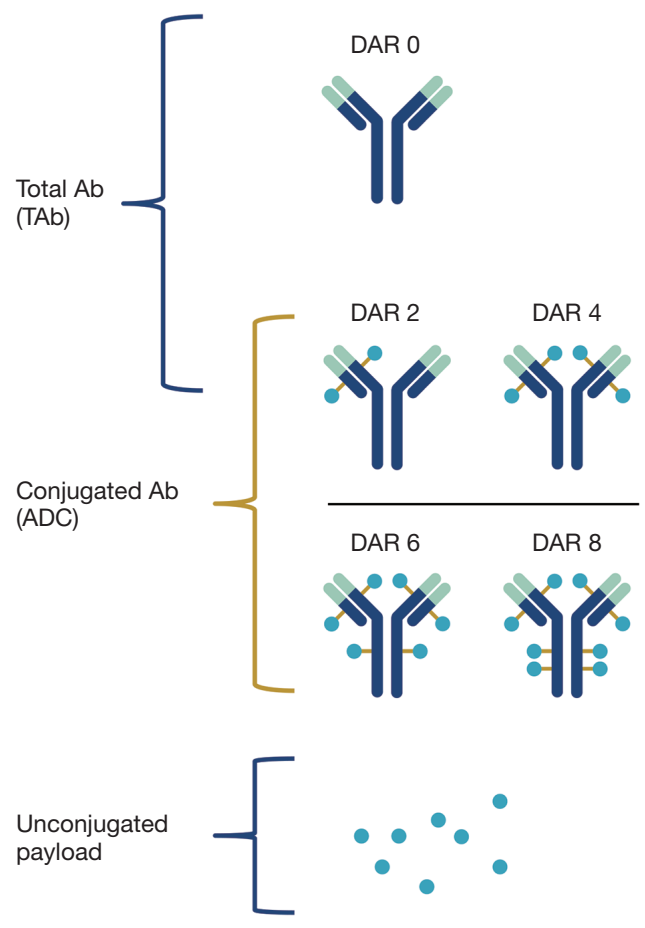

B

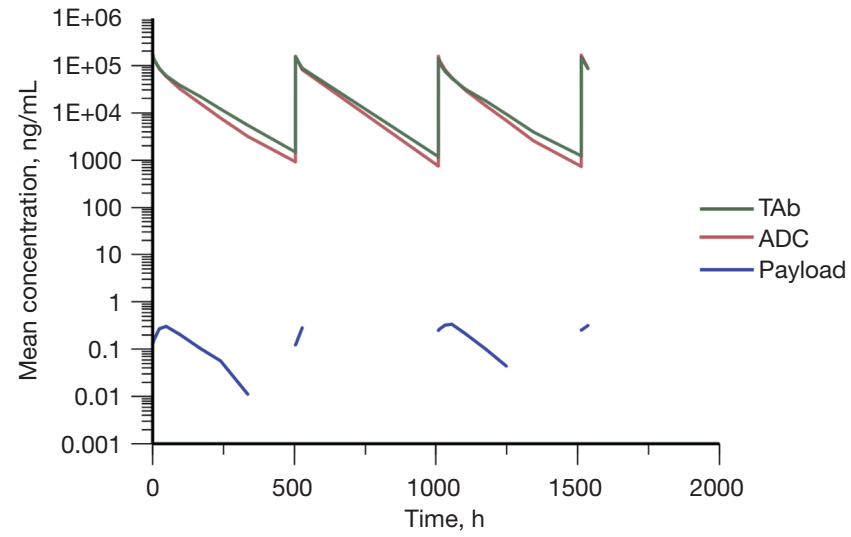

C

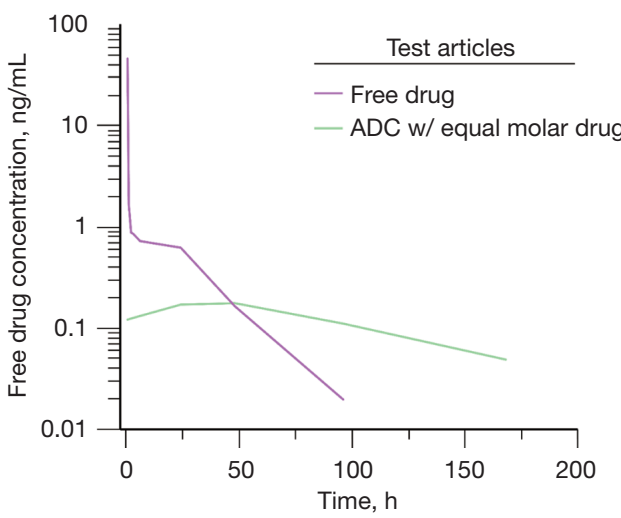

Figure 5 Illustration of ADC analytes and PK profiles of ADC, TAb and payload. (A) Graphic illustration of three analytes of ADC for PK analysis: conjugated antibody (ADC): represented by ADCs with different DAR values, e.g., DAR2, DAR4, DAR6 and DAR8; total antibody (TAb): conjugated $\mathrm{Ab}$ (ADC) species and naked antibody, represented by DAR0; unconjugated payload: released drugs from ADC represented by blue dots. (B) Graphic illustration of PK curves of ADC, TAb and free payload represented by green line, red line and blue line, respectively after repeated doses (q3wx4) administration in NHP. Peak concentration (Cmax) of payload is about 2-3 orders of magnitude lower than that of ADC or TAb. (C) Graphic illustration of PK curve comparing free drug (payload) and ADC with equal molar drug (payload) post drug administration. Purple line represents free drug and green line represents ADC. ADC, antibody drug conjugate; PK, pharmacokinetics; TAb, total antibody; DAR, drug to antibody ratio.

T-DM1 has not been approved for HER2-positive breast cancer patients with brain metastasis (BM), although an exploratory study for this cohort of patients showed active signal in the KAMILLA trial (23). Compared to existing HER2-targeted therapies, Kadcyla ${ }^{\circledR}$ shows clear therapeutic advantages with a mPFS of 9.6 months and a median duration of survival of 30.9 months as reported in EMILIA study. Specifically, Kadcyla ${ }^{\circledR}$ is effective in trastuzumab- or lapatinib-resistant breast cancer (24). However, Kadcyla ${ }^{\circledR}$ still suffers from the challenge of acquired resistance in breast cancer (25). In addition, T-DM1 has a boxed warning of hepatotoxicity, cardiac toxicity and embryo-fetal toxicity.

\section{Trastuzumab deruxtecan}

Fam-trastuzumab deruxtecan (T-DXd, ENHERTU ${ }^{\circledR}$, DS8201) is comprised of trastuzumab, DXd (a topoisermerase inhibitor, a camptothecin analogue) via cleavable maleimide glycine-glycine-phenylalanine-glycine linker (26). It is approved under accelerated approval based on tumor response rate and duration of response for the treatment of adult patients with unresectable or metastatic HER2positive breast cancer who have received two or more prior anti-HER2-based regimens in the metastatic setting. Patients with active brain metastases were excluded in the study (DESTINY-Breast01, NCT03248492). 
Unlike T-DM1, where the released payload is attached to a positively charged lysine residue, thus rendering it cell impermeable, the released DXd from T-DXd is cell permeable, which elicits bystander cell killing. The DESTINY-Breast01 study (NCT03248492) has shown an impressive ORR of $60.9 \%$ and a median progressionfree survival (PFS) of 16.4 months in a heavily pretreated population where all patients had previously received T-DM1 treatment (27). Despite the significant antitumor activities and durable responses obtained, ENHERTU ${ }^{\circledR}$ was reported to cause interstitial lung disease (ILD) in approximately $10 \%$ of patients in a clinical study, which led to death in $2.2 \%$ of those patients. As such, ILD is a safety concern in a boxed warning on the label of ENHERTU ${ }^{\circledR}$.

\section{HER2-targeting ADCs for breast cancer in clinical development}

There are over twenty HER2-targeting ADCs in various stages of clinical development globally as shown in Table 3. Based on publicly available structural information of payloads, five of these ADCs use DM1 as their payload, four use MMAE (Monomethyl auristatin E) and two use MMAF (Monomethyl auristatin F). ZW49, a HER2targeting $\mathrm{ADC}$, also uses an auristatin-derivative, a novel $\mathrm{N}$-acryl sulfonamide auristatin, as its payload conjugated with a biparatopic antibody ZW25 via ZymeLink. ADCs with ZymeLink platform are reported to be more hydrophilic with much enhanced exposure and tolerability $(28,29)$. It appears that microtubule inhibitors are still the most favorable payloads in HER2-targeting ADCs, as approximately half of these ADCs utilize this class of payloads. The chemical structure of the payloads of these ADCs is shown in Table 4, and their properties are summarized below.

\section{Auristatins based ADCs}

Auristatins have been used in many ADCs. Its most studied member, MMAE, is used as the payload in four marketed drugs. Of these four, Adcetris ${ }^{\circledR}$, Polivy $^{\circledR}$ and PADCEV ${ }^{\circledR}$ have been approved by the FDA and disitamab vedotin (RC48-ADC) has been approved by NMPA. In addition, there are more than $10 \mathrm{ADCs}$ utilizing MMAE and MMAF in various phases of clinical development. Other HER2ADCs in clinical development utilizing these chemotypes include MRG002, DP303c, and ALT-P7, while those utilizing MMAF include ARX788 and FS-1502.

\section{Maytansinoid derivatives based ADCs}

Maytansine is a very potent inhibitor for microtubule assembly. Its derivative, DM1, is a well-known payload, which is present in the marketed drug $\mathrm{Kadcyla}^{\circledR}$ for breast cancer treatment. Other HER2-ADCs in clinical development utilizing these chemotypes include: TAA013, SHR-A1201, B003, HS630 and GB251. While BAT8001 was a HER2-ADC using Batansine, another form of maytansine derivative, its phase III trial has since been terminated.

\section{Tubulysins based ADCs}

Tubulysins function by disrupting microtubule polymerization of dividing cells and eventually leading to apoptosis. There are several ADCs in development which carry tubulysins as their payload, but none have yet gained marketing approval. Other tubulin inhibiting agents such as cryptomycins and antimitotic EG5 inhibitors are also used as ADC payloads, though neither have been approved for commercial use. DX126-262, a HER2-targeting ADC that uses Tub114, a derivative of Tubulysins, is currently in its phase 1 trial.

\section{Pyrrolobenzodiazepines (PBDs) and indolinobenzodiazepine based ADCs}

PBDs are a family of antitumor antibiotics that selectively bind in the minor grooves of DNA. Hartley and colleagues reported that PBD dimers exhibit fast clearance after being released from the ADC and are only moderately susceptible to multidrug resistance mechanisms (30). In addition, unlike tubulin inhibitors, PBD dimers demonstrate potent cell killing activity against slow proliferating cells (e.g., tumor initiating cells) and fast dividing cells. All these features have triggered evaluation of PBD dimers in a number of ADCs in clinical development. Loncastuximab tesirine (ADCT-402) is currently the only ADC drug with a PBD dimers payload that has gained FDA approval for relapsed or refractory LBCL with CD19 expression. Similar to $\mathrm{PBD}$, indolinobenzodiazepine has also been used as payload in a number of ADCs in clinical development (31), as reported in a comprehensive review by Mantaj and colleagues (32). Other ADCs in this category include DHES0815A (RG6148), a HER2-targeting ADC developed by Genentech, which uses PBD-MA as its warhead, and ADCT-502, a HER2-targeting ADC developed by ADC Therapeutics, which uses PBD dimers as its payload. While ADC-502 was terminated at Phase I due to safety reasons 
Table 3 Selected HER2-ADCs in clinical development

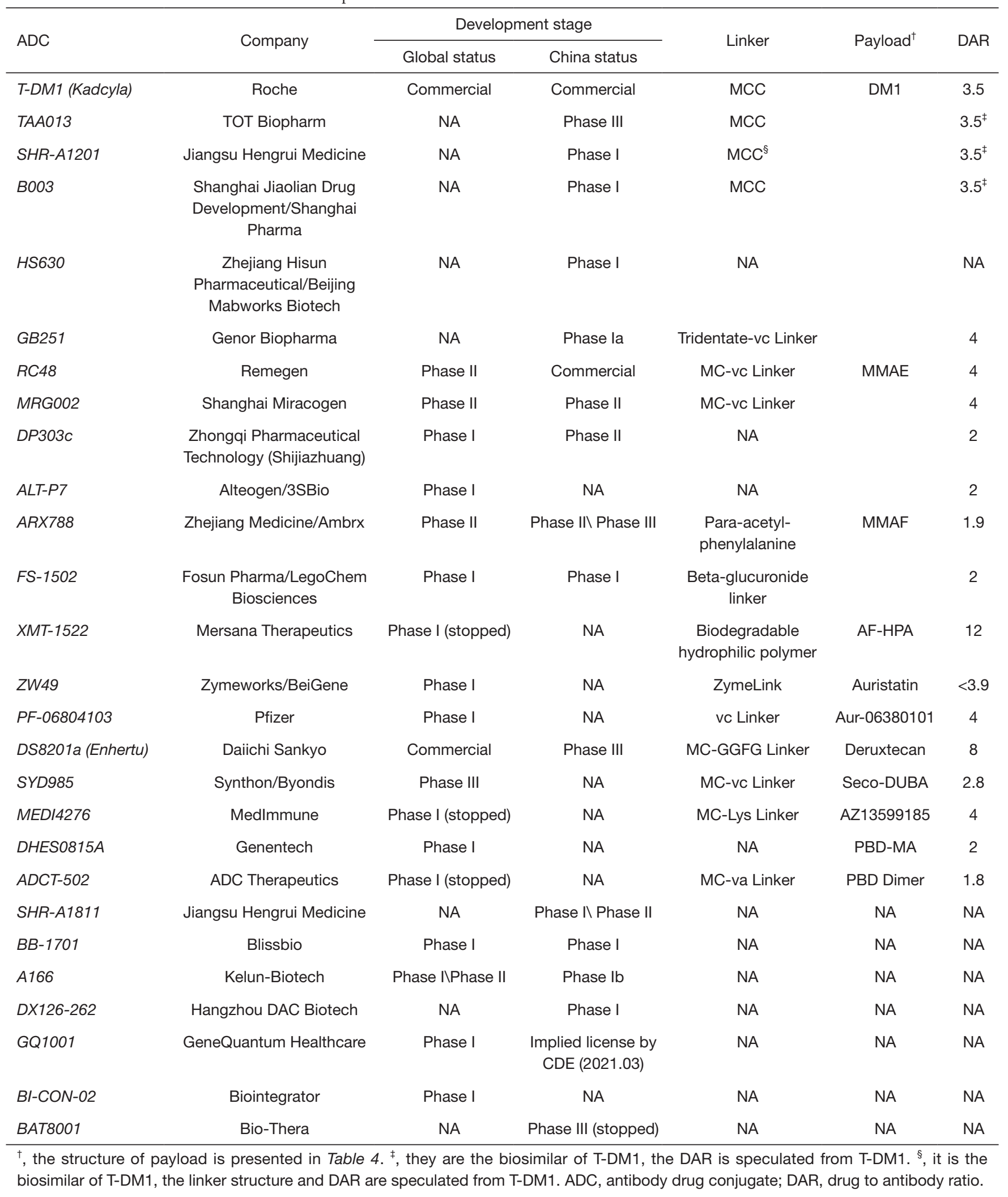


Table 4 Chemical structure of payload for selected HER2-ADCs in development

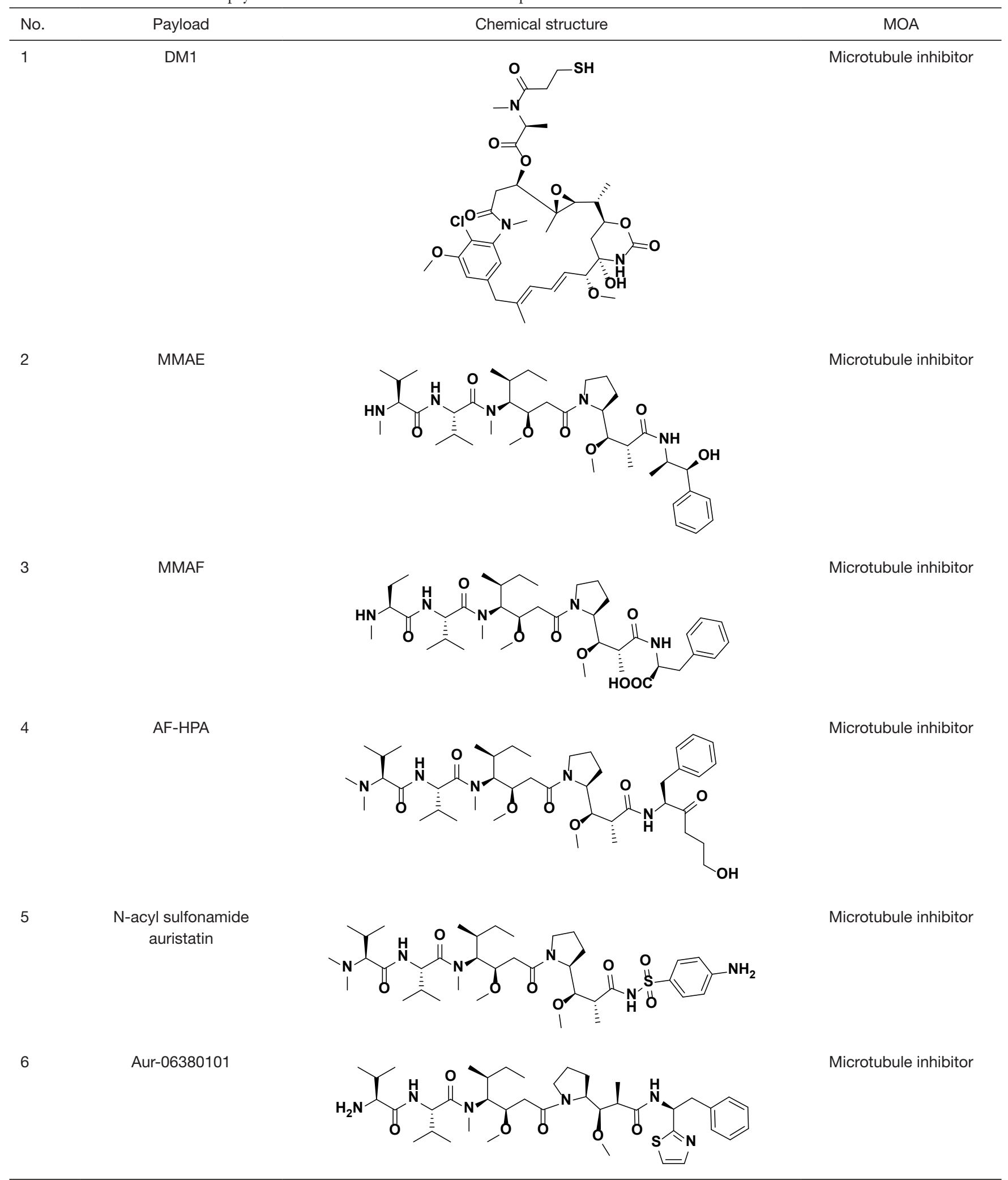

Table 4 (continued) 
Table 4 (continued)

\begin{tabular}{|c|c|c|c|}
\hline No. & Payload & Chemical structure & MOA \\
\hline 8 & Seco-DUBA & $\mathrm{Cl}$ & DNA alkylator \\
\hline 9 & $\begin{array}{c}\text { AZ13599185 (Tubulysin } \\
\text { analogue) }\end{array}$ & $\mathrm{AcO}$ & Microtubule inhibitor \\
\hline 10 & PBD-MA & & DNA alkylator \\
\hline
\end{tabular}

ADC, antibody drug conjugate; MOA, mechanism of action.

(NCT03125200), DHES0815A is still undergoing Phase I evaluation for HER2-positive MBC (NCT03451162).

\section{Duocarmycins based ADCs}

Duocarmycins are potent cytotoxic payloads that have been evaluated in a number of clinical trial ADCs. They bind to DNA minor grooves and alkylate the adenine of the N3 position through their highly reactive cyclopropane ring. SYD985, developed by Synthon/Byondis, is an example of a HER2-targeting ADC using seco-DUBA as its warhead. The drug is currently in Phase III of clinical study
(NCT03262935).

\section{Camptothecin (CPT) derivatives based ADCs}

FDA approval of Trodelvy ${ }^{\circledR}$ (IMMU-132) and ENHERTU ${ }^{\circledR}$ (DS-8201) is proof that CPT and its derivatives can be used as an effective payload for treating solid tumors. This class of molecules are topoisomerase I (TOP1) inhibitors, which inhibit TOP1 activity during DNA replication. The success of utilizing relatively lower potency inhibitors such as CPT with high DAR values $(7,10)$ will likely increase its popularity in future ADC development. 


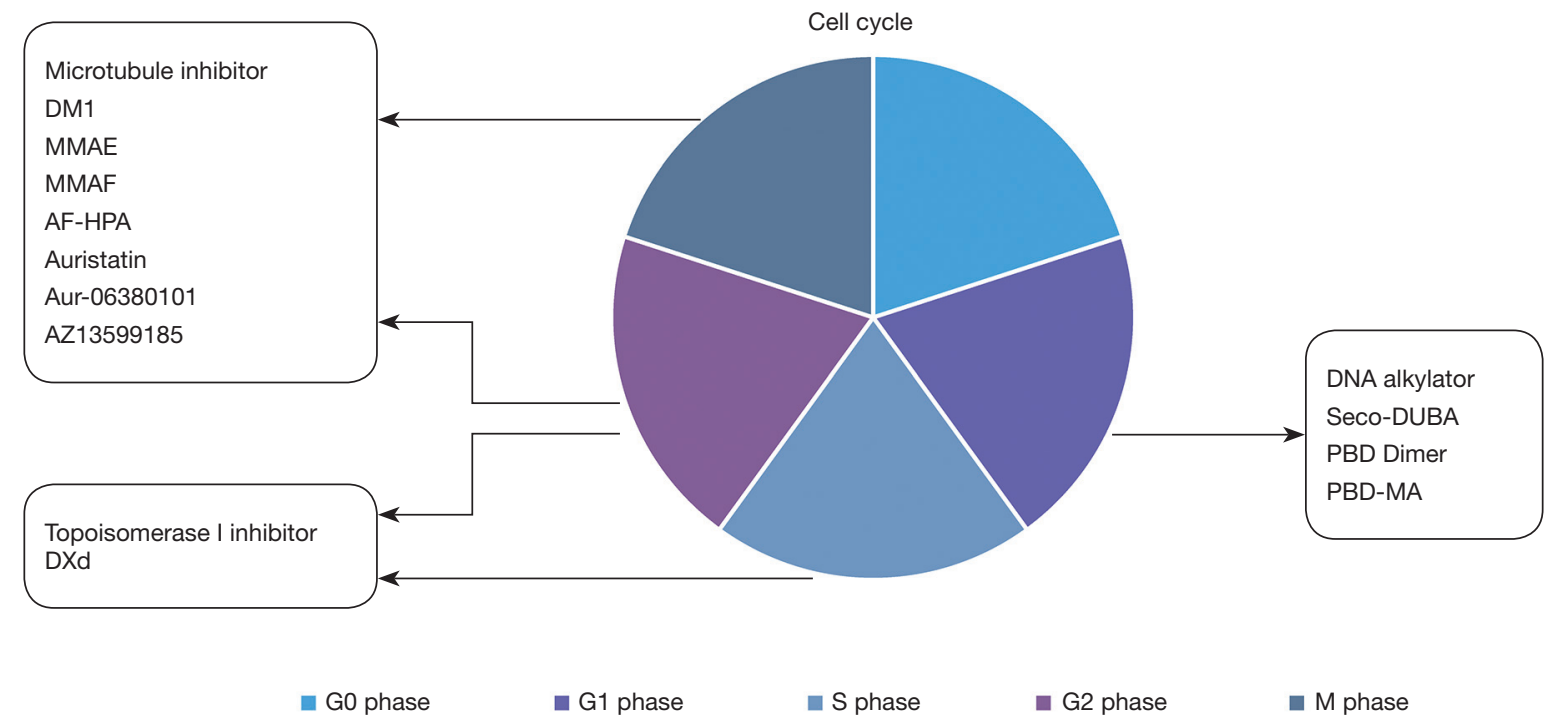

Figure 6 Illustration of action phase of payload on cell cycle. Payloads targeting specific phase (s) of cell life cycle including G0, G1, S, G2 or $M$ phases are group together in boxes and displayed.

\section{Mechanisms of action of cytotoxic payloads and beyond} Cytotoxic agents kill cancer cells by interrupting cell proliferation in various phases of the cell cycle. The specific payload mechanisms in currently approved HER2-targeting ADCs, along with a majority of those still in clinical development, are illustrated in Figure 6. Different payload classes may target different phases of the cell cycle. For example, microtubule inhibitors such as DM1, MMAE, MMAF, AF-HPA and AZ13599185 target the M and G2 phases; DNA alkylators such as Seco-DUBA and PBD dimers target the G1 phase, and Topoisomerase I inhibitors such as DXd and SN-38 target the S and G2 phases.

Besides cytotoxic agents that work by disrupting the cell cycle, thus leading to cell death, small molecules such as apoptosis inducers (e.g., Bcl-xL inhibitors), RNA splicing inhibitors (e.g., thailanstatin and analogues), transcription inhibitors (e.g., amatoxins), and the nicotinamide phosphoribosyltransferase inhibitors have also been reported for use as ADC payloads $(33,34)$. Additionally, small molecule agonists that modulate innate immunity, such as toll-like receptor (TLR) agonists and stimulator of interferon genes protein (STING) agonists, have been also utilized as ADC payloads. Though these novel mechanisms are still in clinical development, they carry the hope of breakthrough treatment options for patients in need (35-38).

\section{Matching DAR with payload}

The DAR value of selected HER2-targeting ADCs is displayed in Table 3. It is worth noting that tubulin-inhibitor conjugated ADCs typically have a DAR of approximately 4 , exemplified by T-DM1 and RC-48. ADCs using more potent payloads, such as PBD dimers, typically have a lower DAR value of around 2 (e.g., ADCT-502 and DHES0815A, which have DAR values of 1.8 and 2, respectively). On the other hand, ADCs using lower potency warheads appear to have a higher DAR value. For example, ENHERTU ${ }^{\circledR}$ (T-DXd, DS-8201) has a DAR of 8, while IMMU-132 (Trodelvy ${ }^{\circledR}$ ) has a DAR of 7-8. The clinical doses of ENHERTU ${ }^{\circledR}$ and Trodelvy ${ }^{\circledR}$ are similar to those of antibody therapeutics, perhaps owing to the lower potency of warheads in this class and a reduced concern for off-target toxicity compared with the tubulin-inhibitor- and PBD dimers based ADCs, and may provide clinical benefits for solid tumors due to potentially better tumor penetration $(39,40)$. Understanding the broad spectrum of payload potency, as well as their specific cell death mechanisms, is the key to better ADC designs that balance both clinical efficacy and safety.

\section{PK experience with MMAE payload}

MMAE payloads are utilized in four marketed ADCs as well as more than half of ADCs in clinical trials (41). Compared with other payloads, the ADME of MMAE in ADCs is 
Table 5 MMAE PK parameters in clinic

\begin{tabular}{|c|c|c|c|c|c|c|c|c|}
\hline Target & Indication & Payload & DAR & Linker & Dosage regimen & Cmax, ng/mL & $A \cup C$, d.ng/mL & $t_{1 / 2}$, days \\
\hline CD79b & DLBCL in comb. & MMAE & 3.5 & $\mathrm{CL}$ & $\begin{array}{l}1.8 \mathrm{mg} / \mathrm{kg} \text { Q3W } \\
\text { (in combination) }\end{array}$ & $\sim 7.2^{\ddagger}$ & $\sim 52^{\ddagger}$ & $4^{\ddagger}$ \\
\hline Nectin-4 & mUrothelial & MMAE & 4 & $\mathrm{CL}$ & $\begin{array}{c}1.25 \mathrm{mg} / \mathrm{kg} \\
(\mathrm{D} 1,8,15 \text { of } \mathrm{Q} 4 \mathrm{~W})\end{array}$ & $\sim 4.79^{\S}$ & $\sim 68.6^{\S}$ & $2.4^{\S}$ \\
\hline HER2 & Gastric cancer & MMAE & 4 & CL & $2.5 \mathrm{mg} / \mathrm{kg}$ Q2W & $\sim 6^{\#}$ & $\sim 41.3^{\#}$ & $\sim 2.6^{\#}$ \\
\hline
\end{tabular}

${ }^{\dagger}$, data sources: https://www.accessdata.fda.gov/drugsatfda_docs/nda/2011/1253990rig1s000ClinPharmR.pdf. ${ }^{\ddagger}$, data sources: https:// www.accessdata.fda.gov/drugsatfda_docs/label/2019/7611210rig1s003lbl.pdf. \$, data sources: https://www.accessdata.fda.gov/ drugsatfda_docs/label/2021/761137s006s008lbl.pdf. ", data sources: ESMO 2017. ", data sources: Xu YY, Wang Y, Gong J, et al. Gastric Cancer (2021) 24:913-925, doi: 10.1007/s10120-021-01168-7. PK, pharmacokinetics; DAR, drug to antibody ratio.

well elucidated (42). Due to the hydrophobicity nature of MMAE, these ADCs typically have a DAR value of $\sim 4$ in order to balance its efficacy and pharmacokinetics (43).

$\mathrm{Li}$ and colleagues investigated the pharmacokinetics of eight vcMMAE ADCs in first-in-human (FIH) studies and explored exposure-response (E-R) relationships of these eight ADCs at $2.4 \mathrm{mg} / \mathrm{kg}$ following first dose (44). The study had four main takeaways: first, the PK profiles of the three analytes following the first dose of $2.4 \mathrm{mg} / \mathrm{kg}$ were comparable across the eight ADCs regardless of the targets for these ADCs (IgG1 antibody moiety) to bind. Second, the exposure differences between molecules were small relative to the inter-subject variation. Third, exposure of the conjugated antibody (ADC) strongly correlated with total antibody exposure for all eight ADCs, but such correlation was less evident between ADC and unconjugated MMAE exposure. Lastly, efficacy and safety endpoints of these ADCs in phase I studies were shown to correlate well with the ADC, but not with unconjugated MMAE. However, it is interesting to note that the Cmax of the unconjugated MMAE of these eight ADCs (DAR 4, $2.4 \mathrm{mg} / \mathrm{kg}$ ) is less than $8 \mathrm{ng} / \mathrm{mL}$, with an AUC between 40 and 60 day.ng/mL and a half-life of $\sim 3-5$ days. These PK parameters of the unconjugated MMAE are similar to reported data of approved vcMMAE ADCs such as brentuximab vedotin, enfortumab vedotin, polatuzumab vedotin and disitamab vedotin (Table 5), as well as our in-house data (unpublished).

\section{HER2-targeting ADCs in combination for BC in clinical trials}

Immune checkpoint inhibitors (IOs) such as anti-PD1 or anti-PD-L1 antibodies have dramatically changed our battle against cancers. Clinical trials of combining ADC and immune check point inhibitors have shown promising outcomes without significant new findings in toxicities. One recent report involves enfortumab vedotin, an anti-Nectin-4 vcMMAE ADC approved for urothelial carcinoma. In combination with pembrolizumab, the treatment showed an impressive $73.3 \%$ ORR, as opposed to the $44 \%$ ORR when used alone (45).

The rationale for supporting combination therapy of ADC and IOs has been studied both preclinically and clinically. Release of a cytotoxic agent induces immune cell death (ICD) in order to alter tumor microenvironment (TME), such as maturation of dendritic cells (DCs) and activation of $\mathrm{T}$ cells (46). ADCs bearing payloads in different classes (such as microtubule-disrupting agents, PBD dimers or tubulysins) have been reported to stimulate functional DC maturation and activation in vivo (47-49). A report described by Müller et al. shows that T-DM1 promoted PD-1 expression in CD8+ T cells and PD-L1 expression in tumor associated macrophages (TAMs) (50) in preclinical settings. The synergistic effect of T-DM1 and CTLA-4/PD-1 was observed in in vivo models. There are approximately $36 \mathrm{ADC}+\mathrm{IO}$ combination clinical trials involving $20 \mathrm{ADC}$ molecules in clinical development (41), since enhanced PD-1 expression after ADC treatment provides a synergistic rationale for ADCs to work with immune check point inhibitors.

This synergistic effect was also observed for anti-HER2 antibody trastuzumab and PD-L1 antibody in a clinical study by Chia et al. (51). In addition to combining with immune checkpoint blockage agents such as PD-1/PD-L1 
and $4-1 \mathrm{BB}, \mathrm{ADCs}$ are also being evaluated in clinical development with other agents with varying mechanisms such as CDK4/6 inhibitors, PI3K inhibitors, PARP inhibitors or TLR agonists for breast cancer, bringing the total combination trials to about 70 (Table S1). It is worth noting that T-DM1 and DS-8201 are two ADCs with the most combination trials registered in clinicaltrials.gov.

\section{Unmet medical needs and potential strategies}

Despite advancements in treatments for patients with HER2positive advanced breast cancers, major challenges still remain. Below, we will explore three: central nerve system (CNS) metastasis, low HER2-expression (which accounts for $40-50 \%$ of breast cancer patients), and drug resistance.

\section{Patients with CNS metastasis}

BM occurs in approximately $30 \%$ of advanced BC patients, and current treatment options are limited $(52,53)$. In addition, brain metastatic patients are often excluded from clinical trials, which limit evaluation of treatment for this metastatic site. Tucatinib exhibited strong efficacy in patients with advanced HER2-positive disease, but added barely 3 months in mFPS compared with the placebo regimen in HER2CLIMB trial (7.8 vs 5.6 months). Patients with HER2-positive MBC have increased risk of developing tumors in CNS than those with HER2-negative (54-56). CNS metastasis is the main cause of advanced breast cancer patient mortality, with $20 \%$ surviving to one year, and less than $2 \%$ surviving to five $(52-54,57,58)$. Due to the intact blood-brain barrier (BBB), most chemo drugs do not penetrate $\mathrm{CNS}$ and therefore are not used routinely for the treatment.

Monoclonal antibodies are reportedly unable to cross an intact human BBB due to their large size. However, BBBs of patients with BM may have been compromised to allow for better drug penetration. In one study, mouse antiEGFR antibody concentrations were shown to be enriched 8-25-fold in tumor vs nonmalignant-brain uptake (59-61). Using ${ }^{125} \mathrm{I}$ labeled trastuzumab in vivo and fluorescent trastuzumab-Rhodamine 123 in vitro in studying BM of breast cancer models, Terrell-Hall and colleagues reported that trastuzumab is able to cross the BBB and accumulate in the tumor albeit in small quantities that do not reach an effective concentration (62). Dijkers et al.'s study showed similar uptake of $89 \mathrm{Zr}$-trastuzumab in HER2-positive BM (63). A preclinical study using hematogenous xenograft models reported by Gril et al. showed that a biparatopic HER2 antibody conjugated with a tubulysin payload (bHER2ATC) prevented JIM-1 BR BM outgrowth and showed activity in the SUM190-BR model although ADC uptake was low and heterogenous in the metastasis area (64).

To date, no clinical trial data support the use of mAbs to treat patients with BM, and any use by physicians is usually off-label. However, patients treated with HER2-targeting $\mathrm{mAb}$ trastuzumab are reported to have better survival benefits indicating $\mathrm{mAb}$ permeability into the BBB (65-67). Retrospective analysis of multiple T-DM1 clinical trials for patients with $\mathrm{BM}$ showed promising outcomes and improvements in overall survival (OS) (68). These studies demonstrate the potential of exploring HER2-targeting ADCs, especially those with better CNS penetration or more effective cytotoxic agent concentration in intracranial tumors. In fact, there are ongoing clinical trials that target HER2-positive breast cancer patients with BM and whose findings will likely bring systemic treatment options for those in need (69).

One potential way to improve BBB penetration would be to develop ADCs with small-sized targeting moieties. Studies have shown that antibody fragments and smaller formats have better penetration due to faster diffusion and extravasation coefficients (70-73). One such example is the use of peptides in peptide-drug conjugates (PDCs) (74). BT5528, a Bicycle Toxin Conjugate targeting EphA2 receptor using MMAE as payload, demonstrated impressive preclinical antitumor activity (75) and is currently in Phase I/II development (NCT04180371). In addition, BT5528 showed a better safety profile in preclinical settings compared to MEDI547, a mc-MMAF conjugated ADC targeting EphA2 whose clinical development was halted at Phase I. In fact, there are many ongoing small-format drug conjugates in clinical and preclinical evaluation that will likely shed light on tackling CNS metastasis of solid tumors (73).

Another way to improve BBB penetration is to include a translocation moiety to the antibody component, such as a cell penetration peptide (CPPs) in $\mathrm{BBB}$ translocation to facilitate the delivery of $\mathrm{ADC}$ to cross the $\mathrm{BBB}(76,77)$. In a study involving BT474 breast cancer mice tumor models, a tethered anti-HER2 mAb with Angiopep-2 (ANG4043), a 19-aa peptide derived from the Kunitz domain which binds to the low-density lipoprotein receptor-related protein 1 (LRP1), demonstrated accumulation in the brain and an overall better treatment outcome compared to the control (78).

Transport vehicle platform technology is currently being evaluated in a few clinical trials for neurodegenerative 
diseases. Developed by Denali therapeutics, these vehicle platforms with engineered transferrin receptor (TfR) binding domain in the constant region of a human IgG1 will bind to the transferrin receptor (TfR) expressing on the endothelial cells of the BBB and ferry the antibody therapeutics, fused on the other end of the vehicle, across $\mathrm{BBB}$ through receptor-mediated transcytosis (RMT). However, it should be cautioned that BBB is different from BTB (blood-tumor barrier), and successful strategies identified for treating neurodegenerative diseases may not be exactly replicated for treating patients with advanced tumors.

\section{HER2-low expression}

HER2-positive is pathologically defined as IHC3+ or IHC2+/ISH+. About $40-50 \%$ of BC patients have lowmedium HER2 expression, which is defined as IHC1+ or IHC2+/ISH- (79-81). In a trial of 54 HER2-low patients with breast cancer, the recently approved ENHERTU ${ }^{\circledR}$ showed promising antitumor activity with an ORR of $37.0 \%$ and a median duration of response of 10.4 months (40). However, the risk of interstitial lung disease (ILD) associated with ENHERTU ${ }^{\circledR}$ will likely hinder its clinical use. Another hurdle faced by patients with HER2-low expression is a reliable method for determining the HER2 level. The frequently used IHC method is semi-quantitative and typically uses archived tumor tissues collected from the patients. However, scoring discrepancies between labs can likely lead to incorrect treatment. Additionally, the storage conditions and length of storage of FFPE blocks of patient tumor tissues, as well as HER2 level changes due to prior treatments, can further exacerbate the situation. A survey conducted in the United States showed that nearly a quarter of patients received inappropriate treatment due to inaccurate test results, with an $18 \%$ average error rate for IHC detection of HER2 protein expression and a $13 \%$ error rate for FISH detection of HER2 gene amplification $(82,83)$. Some studies indicate that HER2 mRNA detection better predicts the neoadjuvant efficacy of trastuzumab in BC patients compared to the IHC method (84). Therefore, a reliable method or biomarker (such as HER2 mRNA) is crucial to finding the best treatment for HER2-low expression patients.

\section{Drug resistance}

Owing to its unique mode of action, acquired drug resistance mechanism of ADC is also complicated. Firstly, the antigen on cell surface can be down-regulated or lost through prior therapies. HER2 expression is reportedly to be lost or down-regulated after HER2-targeted treatment (85). For example, trastuzumab treatments have been associated with changing the HER2 expression from positive to negative in approximately $50 \%$ of cases. Secondly, alteration of intracellular trafficking, such as altered expression of certain endocytic and cytoskeletal proteins, altered lysosomal $\mathrm{pH}$ regulation, or reduced expression of lysosomal transporter proteins, would also cause ADC drug resistance due to inefficient payload release (86). Thirdly, payload intolerance or efflux (e.g., drug-induced upregulation of an ATP binding cassette (ABC) transporter, such as MDR1) as well as upregulation of $\mathrm{P} 450$ enzymes (e.g., CYP3A4) will also likely reduce $\operatorname{ADC}$ efficacy $(87,88)$. For instance, vcMMAE ADCs will encounter resistance in patients whose CYP3A4 is upregulated or induced via coadministrated medicines because MMAE is a substrate of CYP3A4.

Better understanding of de novo or acquired resistance mechanism would provide insights in designing ADC with better efficacy. For example, if the resistance is due to down-regulation of surface antigen on tumor cell surface after prior treatment (89), an ADC with a more potent payload or a higher DAR value will result in more effective drug concentrations and tumor-killing capabilities.

Drug resistance can also be due to altered intracellular trafficking, resulting in impaired internalization or $\mathrm{pH}$ changes that render lysosomes less efficient in degrading the ADC. For these cases, co-expression of proteins in receptormediated endocytosis, such as caveolin-1, may facilitate endocytosis and ADC transport to the lysosome or repair the damaged lysosomal compartment to regain its activity. Chung and colleagues reported that Metformin-induced caveolin-1 expression promoted T-DM1 drug efficacy in preclinical settings (90). Pereira et al. also supported this finding, reporting that depletion of caveolin-1 gene enriched HER2 expression and half-life on the cell surface in HER2-expressing cancel cell lines (91).

Finally, if drug resistance is due to overexpressed P-glycoprotein 1 for a particular chemo or payload type, ADCs with payloads of different MOAs can be tested. Yamazaki and colleagues found that a HER2-targeting dualdrug ADC (MMAE + MMAF) showed superior cell killing and antitumor activity compared to a single-drug payload $\mathrm{ADC}$ in xenograft mice models representing tumor antigen heterogeneity and elevated drug resistance (92). 


\section{Drug penetration in solid tumors}

Tumor penetration and micro-distribution of ADC drugs can be affected by many factors including antigen density on cell surface, binding affinity (on- and off-rate), extracellular matrix (ECM) structure, and receptor internalization rate/ trafficking, among others. The "Binding site barrier" phenomenon has been described as highly expressed receptors where diffused ADC molecules are absorbed by tumor cells close to the blood vessels, leading to diminished drug concentration beyond the barrier (5,70,93-96).

One possible solution to the "Binding site barrier" phenomenon is to add a loading dose of a parent antibody before $\mathrm{ADC}$ administration, thus allowing for better tumor penetration. There are a number of preclinical studies supporting this rationale, including a recent report from Cilliers and colleagues, whereby co-administration of T-DM1 with trastuzumab improved ADC penetration and antitumor activity in the NCI-N87 gastric xenograft model (97). Singh et al. demonstrated similar findings in a study where two ADCs (T-DM1 and trastuzumab-vcMMAE) were co-administrated with and without trastuzumab in different ratios and evaluated for anti-tumor activity in two xenograft models established with NCI-N87 (HER2-high expressing) and MDA-MB-453 (HER2-low expressing). The results show that co-administration of the ADC with a naked antibody resulted in a synergistic effect in HER2-high expressing NCI-N87 cells but not the HER2-low expressing cell line model (98). Similarly, Lu and colleagues observed panitumumab-IRDye800CW as an ADC surrogate in fresh tissues of patients with head and neck cancer and found better tumor penetration of the dye in co-administration of an unconjugated antibody while maintaining tumor uptake (7).

Another potential solution to the "Bind site barrier" phenomenon would be to decrease the DAR value of an ADC, allowing for a higher dose of ADC administration. This has been demonstrated in clinical trials of antiMUC16 ADC, where ORR improved from 17\% to $45 \%$ after increasing a dose from $2.4 \mathrm{mg} / \mathrm{kg}$ (DAR3.5) to 5.2 $\mathrm{mg} / \mathrm{kg}$ (DAR2) $(99,100)$. The recommended high dosages of recently launched TRODELVY ${ }^{\circledR}$ and ENHERTU ${ }^{\circledR}$ for treating solid tumors are in the similar dose range of $\mathrm{mAb}$ therapeutics and is perhaps worth considering when designing future ADC molecules intended for solid tumors.

\section{Conclusions and future perspectives}

HER2-targeting ADCs such as Kadcyla ${ }^{\circledR}$ and ENHERTU ${ }^{\circledR}$ have brought tremendous clinical benefits to patients with advanced breast cancer. In addition, there are many ADCs with different mechanisms of action in various stages of clinical development that will potentially offer patients more treatment options after experiencing acquired resistance with currently available therapies. Although effective treatments for BC patients with CNS metastasis and low HER2 expression are still lacking, ongoing trials of novel HER2-ADCs, alone or with various agents for combination therapy, will bring much hope for these patients (Table 3 and Table S1).

Future development of HER2-targeting ADCs will continue to address patients dealing with CNS metastasis, HER2-low expression, and acquired drug resistance. One potential solution would be to design ADC molecules that would better penetrate in solid tumors and the BBB to address CNS metastasis. This would involve selecting small binding moieties while retaining high binding specificity to the tumor antigen, biparatopic antibodies that recognize different binding epitopes of HER2 ECD to achieve better cell killing, more stable linkers to mitigate off-target toxicity with favorable PK properties, payloads with unique modalities that balance cell killing potency and ADME properties to increase therapeutic index (TI), or designing ADCs with $>1$ payloads of multiple mechanisms of action to overcome heterogeneity of antigen expression within the tumor mass and resistance (92).

Another dimension to consider would be to experiment various treatment regimens including "fractionated dosing strategy" during clinical development to enable patients to undergo multiple rounds of treatment to achieve maximal benefit.

Hinrichs and colleagues found that fractionated dosing schemes demonstrated significant benefit in preclinical studies (101); the re-approval of Mylotarg in 2017 also benefited from this fractionated dosing strategy (101). PADCEV $^{\circledR}$, a vedotin-ADC marketed for urothelial cancer, also uses a fractionated dosing scheme, whereby $1.25 \mathrm{mg} / \mathrm{kg}$ is administrated QWx3, followed by a week-long pausing period. This delicate balance perhaps can be explained by illustration in Figure 7 using MMAE-ADC as an example. As ADC dose level increases, MMAE concentration in blood (and most likely tissues) also increases. The maintenance of effective payload concentration in the circulation after infusion is critical for killing cancer cells and resulting in a positive clinical response. For instance, at dose level 3, in more than 10 days out of the 21-day treatment cycle $(\mathrm{Q} 3 \mathrm{~W})$, payload concentration is below the IC50 line suggesting an inability to eradicate most tumor cells. However, at dose 


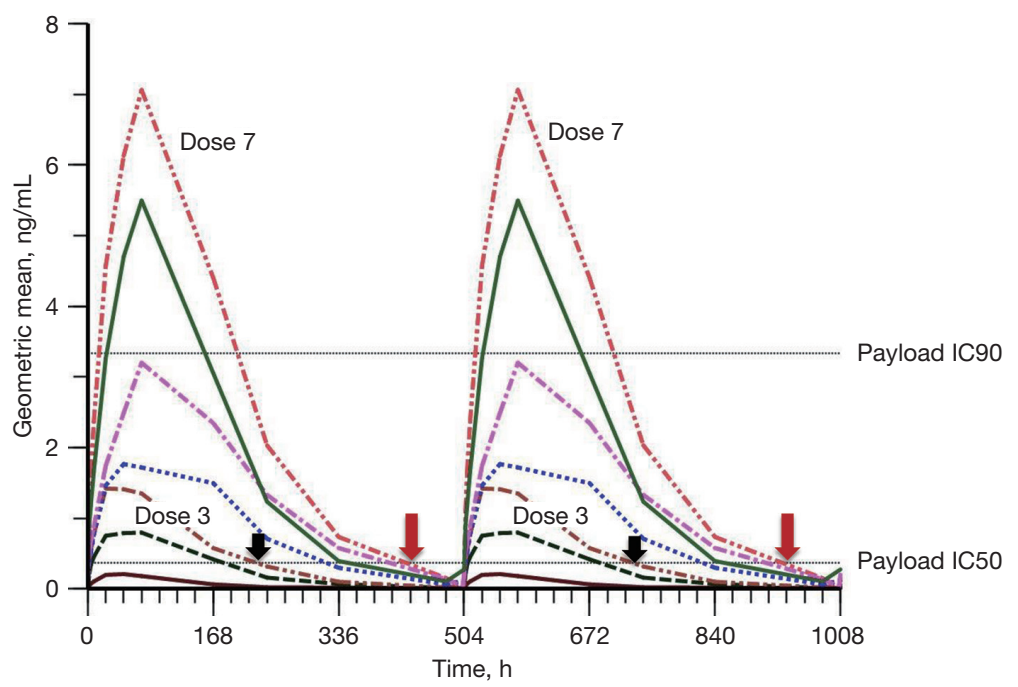

Figure 7 PK profile of free payload in a dose-escalation study in human. Graphic illustration of concentration-time curves of free payload in 7 escalating doses of ADC administration in cycle 1 and cycle 2 in a 3-week dosing regimen in first in human (FIH) study. IC90 and IC50 lines of the payload are putative and for illustration purpose only. Black and red arrows show Day $10(\sim 240$ h) and Day 18 ( 432 h) in each dosing cycle where payload concentration is below IC50 in the curve. PK, pharmacokinetics; ADC, antibody drug conjugate.

level 7, the payload concentration falls below the IC50 line in only 2 out of 21 days. If the ADC were dosed weekly at dose level 3 instead of Q3W, the payload concentration in the circulation would maintain above the IC50 line all times, effectively killing tumor cells and producing a significant clinical response. This potential strategy could be applied to solid tumors.

It is highly expected that novel HER2-targeting ADCs, whether alone or in combination with other agents in development, will bring breakthrough therapies and perhaps even ultimate cures for patients with advanced breast cancer.

\section{Acknowledgments}

We wish to thank our colleagues Fangyuan Zou, Shoujia Liu, Ying Lei and Xiaojing Shi for their assistance in gathering information for some tables and figures used in this review. We are grateful to Mary Hu for critically reviewing the manuscript and providing insightful comments and suggestions for revision.

Funding: None.

\section{Footnote}

Reporting Checklist: The authors have completed the Narrative Review reporting checklist. Available at https:// dx.doi.org/10.21037/tbcr-21-22
Peer Review File: Available at https://dx.doi.org/10.21037/ tbcr-21-22

Conflicts of Interest: Both authors have completed the ICMJE uniform disclosure form (available at https://dx.doi. org/10.21037/tbcr-21-22). The authors have no conflicts of interest to declare.

Ethical Statement: The authors are accountable for all aspects of the work in ensuring that questions related to the accuracy or integrity of any part of the work are appropriately investigated and resolved.

Open Access Statement: This is an Open Access article distributed in accordance with the Creative Commons Attribution-NonCommercial-NoDerivs 4.0 International License (CC BY-NC-ND 4.0), which permits the noncommercial replication and distribution of the article with the strict proviso that no changes or edits are made and the original work is properly cited (including links to both the formal publication through the relevant DOI and the license). See: https://creativecommons.org/licenses/by-nc-nd/4.0/.

\section{References}

1. Ponziani S, Di Vittorio G, Pitari G, et al. Antibody-Drug Conjugates: The New Frontier of Chemotherapy. Int J 
Mol Sci 2020;21:5510.

2. Walsh SJ, Bargh JD, Dannheim FM, et al. Site-selective modification strategies in antibody-drug conjugates. Chem Soc Rev 2021;50:1305-53.

3. Baah S, Laws M, Rahman KM. Antibody-Drug Conjugates-A Tutorial Review. Molecules 2021;26:2943.

4. Verkade JMM, Wijdeven MA, Van Geel R, et al. A Polar Sulfamide Spacer Significantly Enhances the Manufacturability, Stability, and Therapeutic Index of Antibody-Drug Conjugates. Antibodies (Basel) 2018;7:12.

5. Thurber GM, Dane Wittrup K. A mechanistic compartmental model for total antibody uptake in tumors. J Theor Biol 2012;314:57-68.

6. Chari RV. Targeted cancer therapy: conferring specificity to cytotoxic drugs. Acc Chem Res 2008;41:98-107.

7. Lu G, Nishio N, van den Berg NS, et al. Co-administered antibody improves penetration of antibody-dye conjugate into human cancers with implications for antibody-drug conjugates. Nat Commun 2020;11:5667.

8. Damelin M. editor. Innovations for Next-Generation Antibody-Drug Conjugates. Cham: Springer International Publishing, 2018.

9. Kostova V, Désos P, Starck JB, et al. The Chemistry Behind ADCs. Pharmaceuticals 2021;14:442-87.

10. Informa PharmaProjects Database. Available online: https://pharmaintelligence.informa.com/products-andservices/data-and-analysis/pharmaprojects. accessed on August 09, 2021.

11. S9 Implementation Working Group. ICH S9 Guideline: Nonclinical Evaluation for Anticancer Pharmaceuticals Questions and Answers. Current step 4 version, 2018.

12. Han TH, Zhao B. Absorption, distribution, metabolism, and excretion considerations for the development of antibody-drug conjugates. Drug Metab Dispos 2014;42:1914-20.

13. Shah DK, Haddish-Berhane N, Betts A. Bench to bedside translation of antibody drug conjugates using a multiscale mechanistic PK/PD model: a case study with brentuximabvedotin. J Pharmacokinet Pharmacodyn 2012;39:643-59.

14. Shah DK, King LE, Han X, et al. A priori prediction of tumor payload concentrations: preclinical case study with an auristatin-based anti-5T4 antibody-drug conjugate. AAPS J 2014;16:452-63.

15. Yan M, Parker BA, Schwab R, et al. HER2 aberrations in cancer: implications for therapy. Cancer Treat Rev 2014;40:770-80.

16. Yarden Y, Sliwkowski MX. Untangling the ErbB signalling network. Nat Rev Mol Cell Biol 2001;2:127-37.
17. Ross JS, Slodkowska EA, Symmans WF, et al. The HER2 receptor and breast cancer: ten years of targeted antiHER-2 therapy and personalized medicine. Oncologist 2009; 14:320-68.

18. Witton CJ, Reeves JR, Going JJ, et al. Expression of the HER1-4 family of receptor tyrosine kinases in breast cancer. J Pathol 2003;200:290-7.

19. Bang YJ, Van Cutsem E, Feyereislova A, et al. Trastuzumab in combination with chemotherapy versus chemotherapy alone for treatment of HER2-positive advanced gastric or gastro-oesophageal junction cancer (ToGA): a phase 3, open-label, randomised controlled trial. Lancet 2010;376:687-97.

20. Chan CT, Metz MZ, Kane SE. Differential sensitivities of trastuzumab (Herceptin)-resistant human breast cancer cells to phosphoinositide-3 kinase (PI-3K) and epidermal growth factor receptor (EGFR) kinase inhibitors. Breast Cancer Res Treat 2005;91:187-201.

21. Burris HA 3rd, Tibbitts J, Holden SN, et al. Trastuzumab emtansine (T-DM1): a novel agent for targeting HER2+ breast cancer. Clin Breast Cancer 2011;11:275-82.

22. Lewis Phillips GD, Li G, Dugger DL, et al. Targeting HER2-positive breast cancer with trastuzumab-DM1, an antibody-cytotoxic drug conjugate. Cancer Res 2008;68:9280-90.

23. Montemurro F, Delaloge S, Barrios CH, et al. Trastuzumab emtansine (T-DM1) in patients with HER2-positive metastatic breast cancer and brain metastases: exploratory final analysis of cohort 1 from KAMILLA, a single-arm phase IIIb clinical trial . Ann Oncol 2020;31:1350-8.

24. Ballantyne A, Dhillon S. Trastuzumab emtansine: first global approval. Drugs 2013;73:755-65.

25. Barok M, Joensuu H, Isola J. Trastuzumab emtansine: mechanisms of action and drug resistance. Breast Cancer Res 2014;16:209.

26. Ogitani Y, Aida T, Hagihara K, et al. DS-8201a, A Novel HER2-Targeting ADC with a Novel DNA Topoisomerase I Inhibitor, Demonstrates a Promising Antitumor Efficacy with Differentiation from T-DM1. Clin Cancer Res 2016;22:5097-108.

27. Modi S, Saura C, Yamashita T, et al. Trastuzumab Deruxtecan in Previously Treated HER2-Positive Breast Cancer. N Engl J Med 2020;382:610-21.

28. ZW49, a HER2-targeted biparatopic antibody-drug conjugate for the treatment of HER2-expressing cancers. Cancer Res 2018;78:Abstract nr 3914.

29. ZW49, a HER2 targeted biparatopic antibody drug conjugate for the treatment of HER2 expressing cancers. 
Cancer Res 2019;79:Abstract nr P6-17-13.

30. Hartley JA, Flynn MJ, Bingham JP, et al. Pre-clinical pharmacology and mechanism of action of SG3199, the pyrrolobenzodiazepine (PBD) dimer warhead component of antibody-drug conjugate (ADC) payload tesirine. Sci Rep 2018;8:10479.

31. Reid EE, Archer KE, Shizuka M, et al. Effect of Linker Stereochemistry on the Activity of Indolinobenzodiazepine Containing Antibody-Drug Conjugates (ADCs). ACS Med Chem Lett 2019;10:1193-7.

32. Mantaj J, Jackson PJ, Rahman KM, et al. From Anthramycin to Pyrrolobenzodiazepine (PBD)-Containing Antibody-Drug Conjugates (ADCs). Angew Chem Int Ed Engl 2017;56:462-88.

33. Puthenveetil S, Loganzo F, He H, et al. Natural Product Splicing Inhibitors: A New Class of AntibodyDrug Conjugate (ADC) Payloads. Bioconjug Chem 2016;27:1880-8.

34. Karpov AS, Abrams T, Clark S, et al. Nicotinamide Phosphoribosyltransferase Inhibitor as a Novel Payload for Antibody-Drug Conjugates. ACS Med Chem Lett 2018;9:838-42.

35. Ackerman SE, Pearson CI, Gregorio JD, et al. Immunestimulating antibody conjugates elicit robust myeloid activation and durable antitumor immunity. Nature Cancer 2021, 2, 18-33

36. Robert BP, Alan CC, Badreddin E, et al. Antibody construct conjugates [p]. WO2018227023A1, 2018.12.13.

37. Robert BP, Finley DR, Valerie O, et al. Conjugates and methods of use thereof for selective delivery of immunemodulatory agents. WO2019084060A1, 2019.05.02.

38. Amouzegar A, Chelvanambi M, Filderman JN, et al. STING Agonists as Cancer Therapeutics. Cancers (Basel) 2021;13:2695.

39. Kalinsky K, Diamond JR, Vahdat LT, et al. Sacituzumab govitecan in previously treated hormone receptor-positive/ HER2-negative metastatic breast cancer: final results from a phase I/II, single-arm, basket trial. Ann Oncol 2020;31:1709-18.

40. Modi S, Park H, Murthy RK, et al. Antitumor Activity and Safety of Trastuzumab Deruxtecan in Patients With HER2-Low-Expressing Advanced Breast Cancer: Results From a Phase Ib Study. J Clin Oncol 2020;38:1887-96.

41. Coats S, Williams M, Kebble B, et al. AntibodyDrug Conjugates: Future Directions in Clinical and Translational Strategies to Improve the Therapeutic Index. Clin Cancer Res 2019;25:5441-8.

42. Yip V, Lee MV, Saad OM, et al. Preclinical
Characterization of the Distribution, Catabolism, and Elimination of a Polatuzumab Vedotin-Piiq (POLIVY ${ }^{\circledR}$ ) Antibody-Drug Conjugate in Sprague Dawley Rats. J Clin Med 2021;10:1323.

43. Buecheler JW, Winzer M, Tonillo J, et al. Impact of Payload Hydrophobicity on the Stability of AntibodyDrug Conjugates. Mol Pharm 2018;15:2656-64.

44. Li C, Zhang C, Li Z, et al. Clinical pharmacology of vcMMAE antibody-drug conjugates in cancer patients: learning from eight first-in-human Phase 1 studies. MAbs 2020;12:1699768.

45. Rosenberg JE, Flaiq TW, Friedlander TW, et al. Study EV-103 preliminary durability results of enfortumab vedotin plus pembrolizumab for locally advanced or metastatic urothelial carcinoma. J Clin Oncol 2020;38:suppl 441.

46. Gerber HP, Sapra P, Loganzo F, et al. Combining antibodydrug conjugates and immune-mediated cancer therapy: What to expect? Biochem Pharmacol 2016;102:1-6.

47. Müller P, Martin K, Theurich S, et al. Microtubuledepolymerizing agents used in antibody-drug conjugates induce antitumor immunity by stimulation of dendritic cells. Cancer Immunol Res 2014;2:741-55.

48. Martin K, Müller P, Schreiner J, et al. The microtubuledepolymerizing agent ansamitocin P3 programs dendritic cells toward enhanced anti-tumor immunity. Cancer Immunol Immunother 2014;63:925-38.

49. Rios-Doria J, Harper J, Rothstein R, et al. Antibody-Drug Conjugates Bearing Pyrrolobenzodiazepine or Tubulysin Payloads Are Immunomodulatory and Synergize with Multiple Immunotherapies. Cancer Res 2017;77:2686-98.

50. Müller P, Kreuzaler M, Khan T, et al. Trastuzumab emtansine (T-DM1) renders HER2 + breast cancer highly susceptible to CTLA-4/PD-1 blockade. Sci Transl Med 2015;7:315ra188.

51. Chia SKL, Bedard PL, Hilton J, et al. A phase I study of a PD-L1 antibody (Durvalumab) in combination with trastuzumab in HER-2 positive metastatic breast cancer (MBC) progressing on prior anti HER-2 therapies (CCTG IND.229) [NCT02649686]. J Clin Oncol 2018;36:1029.

52. Brufsky AM, Mayer M, Rugo HS, et al. Central nervous system metastases in patients with HER2-positive metastatic breast cancer: incidence, treatment, and survival in patients from registHER. Clin Cancer Res 2011;17:4834-43.

53. Tsukada Y, Fouad A, Pickren JW, et al. Central nervous system metastasis from breast carcinoma. Autopsy study. Cancer 1983;52:2349-54. 
54. Leyland-Jones B. Human epidermal growth factor receptor 2-positive breast cancer and central nervous system metastases. J Clin Oncol 2009;27:5278-86.

55. Kaal EC, Vecht CJ. CNS complications of breast cancer: current and emerging treatment options. CNS Drugs 2007;21:559-79.

56. Gabos Z, Sinha R, Hanson J, et al. Prognostic significance of human epidermal growth factor receptor positivity for the development of brain metastasis after newly diagnosed breast cancer. J Clin Oncol 2006;24:5658-63.

57. Witzel I, Oliveira-Ferrer L, Pantel K, et al. Breast cancer brain metastases: biology and new clinical perspectives. Breast Cancer Res 2016;18:8.

58. Lin NU, Bellon JR, Winer EP. CNS metastases in breast cancer. J Clin Oncol 2004;22:3608-17.

59. Zalutsky MR, Moseley RP, Coakham HB, et al. Pharmacokinetics and tumor localization of 131I-labeled anti-tenascin monoclonal antibody 81C6 in patients with gliomas and other intracranial malignancies. Cancer Res 1989;49:2807-13.

60. Kalofonos HP, Pawlikowska TR, Hemingway A, et al. Antibody guided diagnosis and therapy of brain gliomas using radiolabeled monoclonal antibodies against epidermal growth factor receptor and placental alkaline phosphatase. J Nucl Med 1989;30:1636-45.

61. Zalutsky MR, Moseley RP, Benjamin JC, et al. Monoclonal antibody and $\mathrm{F}\left(\mathrm{ab} \mathrm{b}^{\prime}\right) 2$ fragment delivery to tumor in patients with glioma: comparison of intracarotid and intravenous administration. Cancer Res 1990;50:4105-10.

62. Terrell-Hall TB, Nounou MI, El-Amrawy F, et al. Trastuzumab distribution in an in-vivo and in-vitro model of brain metastases of breast cancer. Oncotarget 2017;8:83734-44.

63. Dijkers EC, Oude Munnink TH, Kosterink JG, et al. Biodistribution of $89 \mathrm{Zr}$-trastuzumab and PET imaging of HER2-positive lesions in patients with metastatic breast cancer. Clin Pharmacol Ther 2010;87:586-92.

64. Gril B, Wei D, Zimmer AS, et al. HER2 antibodydrug conjugate controls growth of breast cancer brain metastases in hematogenous xenograft models, with heterogeneous blood-tumor barrier penetration unlinked to a passive marker. Neuro Oncol 2020;22:1625-36.

65. Pie kowski T, Zielinski CC. Trastuzumab treatment in patients with breast cancer and metastatic CNS disease. Ann Oncol 2010;21:917-24.

66. Dawood S, Broglio K, Esteva FJ, et al. Defining prognosis for women with breast cancer and CNS metastases by HER2 status. Ann Oncol 2008;19:1242-8.
67. Nam BH, Kim SY, Han HS, et al. Breast cancer subtypes and survival in patients with brain metastases. Breast Cancer Res 2008;10:R20.

68. Krop IE, Lin NU, Blackwell K, et al. Trastuzumab emtansine (T-DM1) versus lapatinib plus capecitabine in patients with HER2-positive metastatic breast cancer and central nervous system metastases: a retrospective, exploratory analysis in EMILIA. Ann Oncol 2015;26:113-9.

69. Zimmer AS, Van Swearingen AED, Anders CK. HER2positive breast cancer brain metastasis: A new and exciting landscape. Cancer Rep (Hoboken) 2020:e1274.

70. Rudnick SI, Lou J, Shaller CC, et al. Influence of affinity and antigen internalization on the uptake and penetration of Anti-HER2 antibodies in solid tumors. Cancer Res 2011;71:2250-9.

71. Yokota T, Milenic DE, Whitlow M, et al. Rapid tumor penetration of a single-chain $\mathrm{Fv}$ and comparison with other immunoglobulin forms. Cancer Res 1992;52:3402-8.

72. Dennis MS, Jin H, Dugger D, et al. Imaging tumors with an albumin-binding Fab, a novel tumor-targeting agent. Cancer Res 2007;67:254-61.

73. Deonarain MP, Yahioglu G, Stamati I, et al. Small-Format Drug Conjugates: A Viable Alternative to ADCs for Solid Tumours? Antibodies (Basel) 2018;7:16.

74. Cooper BM, Iegre J, O' Donovan DH, et al. Peptides as a platform for targeted therapeutics for cancer: peptide-drug conjugates (PDCs). Chem Soc Rev 2021;50:1480-94.

75. Bennett G, Brown A, Mudd G, et al. MMAE Delivery Using the Bicycle Toxin Conjugate BT5528. Mol Cancer Ther 2020;19:1385-94.

76. Stalmans S, Bracke N, Wynendaele E, et al. CellPenetrating Peptides Selectively Cross the Blood-Brain Barrier In Vivo. PLoS One 2015;10:e0139652.

77. Oller-Salvia B, Sánchez-Navarro M, Giralt E, et al. Bloodbrain barrier shuttle peptides: an emerging paradigm for brain delivery. Chem Soc Rev 2016;45:4690-707.

78. Regina A, Demeule M, Tripathy S, et al. ANG4043, a novel brain-penetrant peptide-mAb conjugate, is efficacious against HER2-positive intracranial tumors in mice. Mol Cancer Ther 2015;14:129-40.

79. Giuliani S, Ciniselli CM, Leonardi E, et al. In a cohort of breast cancer screened patients the proportion of HER2 positive cases is lower than that earlier reported and pathological characteristics differ between HER2 $3+$ and HER2 2+/Her2 amplified cases. Virchows Arch 2016;469:45-50.

80. Lal P, Salazar PA, Hudis CA, et al. HER-2 testing in breast cancer using immunohistochemical analysis and 
fluorescence in situ hybridization: a single-institution experience of 2,279 cases and comparison of dual-color and single-color scoring. Am J Clin Pathol 2004;121:631-6.

81. Schalper KA, Kumar S, Hui P, et al. A retrospective population-based comparison of HER2 immunohistochemistry and fluorescence in situ hybridization in breast carcinomas: impact of 2007 American Society of Clinical Oncology/College of American Pathologists criteria. Arch Pathol Lab Med 2014;138:213-9.

82. Kaufman PA, Bloom KJ, Burris H, et al. Assessing the discordance rate between local and central HER2 testing in women with locally determined HER2-negative breast cancer. Cancer 2014;120:2657-64.

83. Bogen SA. A Root Cause Analysis Into the High Error Rate in Clinical Immunohistochemistry. Appl Immunohistochem Mol Morphol 2019;27:329-38.

84. Denkert C, Huober J, Loibl S, et al. HER2 and ESR1 mRNA expression levels and response to neoadjuvant trastuzumab plus chemotherapy in patients with primary breast cancer. Breast Cancer Res 2013;15:R11.

85. Ignatov T, Gorbunow F, Eggemann H, et al. Loss of HER2 after HER2-targeted treatment. Breast Cancer Res Treat 2019;175:401-8.

86. Hunter FW, Barker HR, Lipert B, et al. Mechanisms of resistance to trastuzumab emtansine (T-DM1) in HER2positive breast cancer. Br J Cancer 2020;122:603-12.

87. Loganzo F, Sung M, Gerber HP. Mechanisms of Resistance to Antibody-Drug Conjugates. Mol Cancer Ther 2016;15:2825-34.

88. Khongorzul P, Ling CJ, Khan FU, et al. Antibody-Drug Conjugates: A Comprehensive Review. Mol Cancer Res 2020;18:3-19.

89. Drago JZ, Modi S, Chandarlapaty S. Unlocking the potential of antibody-drug conjugates for cancer therapy. Nat Rev Clin Oncol 2021;18:327-44.

90. Chung YC, Chang CM, Wei WC, et al. Metformininduced caveolin-1 expression promotes T-DM1 drug efficacy in breast cancer cells. Sci Rep 2018;8:3930.

91. Pereira PMR, Sharma SK, Carter LM, et al. Caveolin-1 mediates cellular distribution of HER2 and affects

doi: $10.21037 /$ tbcr-21-22

Cite this article as: $\mathrm{Li} \mathrm{H}, \mathrm{Li} \mathrm{H}$. A narrative review of the current landscape and future perspectives of HER2-targeting antibody drug conjugates for advanced breast cancer. Transl Breast Cancer Res 2021;2:29. trastuzumab binding and therapeutic efficacy. Nat Commun 2018;9:5137.

92. Yamazaki CM, Yamaguchi A, Anami Y, et al. Antibodydrug conjugates with dual payloads for combating breast tumor heterogeneity and drug resistance. Nat Commun 2021;12:3528.

93. Jain RK. The Eugene M. Landis Award Lecture 1996. Delivery of molecular and cellular medicine to solid tumors. Microcirculation 1997;4:1-23.

94. Vasalou C, Helmlinger G, Gomes B. A mechanistic tumor penetration model to guide antibody drug conjugate design. PLoS One 2015;10:e0118977.

95. Thurber GM, Schmidt MM, Wittrup KD. Antibody tumor penetration: transport opposed by systemic and antigen-mediated clearance. Adv Drug Deliv Rev 2008;60:1421-34.

96. Adams GP, Schier R, McCall AM, et al. High affinity restricts the localization and tumor penetration of singlechain fv antibody molecules. Cancer Res 2001;61:4750-5.

97. Cilliers C, Menezes B, Nessler I, et al. Improved Tumor Penetration and Single-Cell Targeting of AntibodyDrug Conjugates Increases Anticancer Efficacy and Host Survival. Cancer Res 2018;78:758-68.

98. Singh AP, Guo L, Verma A, et al. Antibody Coadministration as a Strategy to Overcome Binding-Site Barrier for ADCs: a Quantitative Investigation. AAPS J 2020;22:28.

99. Liu JF, Moore KN, Birrer MJ, et al. Phase I study of safety and pharmacokinetics of the anti-MUC16 antibodydrug conjugate DMUC5754A in patients with platinumresistant ovarian cancer or unresectable pancreatic cancer. Ann Oncol 2016;27:2124-30.

100. Moore K, Hamilton EP, Burris HA, et al. Abstract CT036: Targeting MUC16 with the THIOMABTMdrug conjugate DMUC4064A in patients with platinumresistant ovarian cancer: A phase I expansion study. Cancer Res 2018;78:Abstract nr CT036.

101.Hinrichs MJM, Ryan PM, Zheng B, et al. Fractionated Dosing Improves Preclinical Therapeutic Index of Pyrrolobenzodiazepine-Containing Antibody Drug Conjugates. Clin Cancer Res 2017;23:5858-68. 
